\title{
VERSIONING GOODS AND JOINT PURCHASE: SUBSTITUTION AND COMPLEMENTARITY STRATEGIES
}

\section{Francisco Martínez-Sánchez*}

\begin{abstract}
In the present paper, we develop a monopoly model of vertical product differentiation for analysing the monopolist's decision about the possibility of versioning goods as substitutes or complements when consumers can buy them simultaneously. In this context, we find that versioning goods as substitutes or complements is optimal for the monopolist if the cost of designing the bundle (the purchase of one unit of each version) is increasing, which implies that making variants of closer substitutes reduces costs. However, if making variants of closer substitutes is costly, the monopolist versions goods as complements only. The final result also depends on the degree of concavity and convexity of the cost function.
\end{abstract}

Keywords: versioning information goods, joint purchase option, substitutes, complementarity, price discrimination, market segmentation

JEL Classification: L10, L12, L15

\section{Introduction}

A common strategy for most firms is to create various versions of the same product (which is known as versioning goods) for price discriminating purposes and to increase profits, particularly in the industry of information goods (Varian, 2001a; Varian, 2001b, and Belleflamme, 2005). Nevertheless, we believe that this strategy has not been used to the full by some firms insofar as they only pay attention to introducing a new low-quality variant (or version) on the market and fail to consider the possibility of making complementary or substitute variants so that consumers can buy them simultaneously. We refer to this possibility or strategy as versioning substitute/complementary goods.

In the present paper, we analyse the monopolist's decision about the possibility of versioning goods as substitutes or complements when consumers can buy them simultaneously. To understand the strategy of versioning substitute/complementary goods better, we give some examples of the implementation of this strategy in the movie, software and textile industries. We first consider the movie industry. As we can observe, in the last years it is frequent to find several versions of a movie: a standard version for the general public and an extended version (or edition) for a public that value the movie a lot. Normally, the extended version consists of a larger duration (around twenty minutes more), false takes, interviews with the director, actors ... of the movie, etc. Thus, the monopolist encourages

* Francisco Martínez-Sánchez, Department of Quantitative Methods for Economics and Business,

Faculty of Economics and Business, University of Murcia, Murcia, Spain (fms@um.es).

I thank Paul Belleflamme, Natalia Jiménez and two anonymous referees for their useful comments and suggestions. I acknowledge the financial support from the Spanish Ministry of Economy and Competitiveness under Projects ECO2010-19830 and ECO2013-45698. Any remaining errors are, of course, mine. 
consumers to buy both variants. The instruments used to that end can be providing a higher quality, incorporating complementary material, and delaying the launch on the market of the extended version.

Another interesting example within the movie industry is borrowed from Nalebuff and Ayres (2003). These authors suggest that Hollywood can make two versions of its movies: one version for children that omits some unpleasant stages or replaces some unpleasant words according to parents' opinion, for instance sex and violence, and another not censored version for adults. In this case, Hollywood can design the two versions for encouraging families, with a higher willingness to pay for the film, buy them simultaneously.

Secondly we consider a monopolist that develops two vertically differentiated versions of a software product, in which quality is denoted by the number of applications that they can run (Deneckere and McAfee, 1996; and Gabszewicz and Wauthy, 2003). ${ }^{1}$ The monopolist can design the low-quality version in a way that it encourages users to buy the full (or high) version once they are locked in. As in movie industry the monopolist can use the delay of the full version for encouraging the joint purchase.

Finally we consider women's decisions as to what quality-differentiated new dresses to buy, where they can be substitutes if they are similar in style and colours, or complementary if they are in different colours, for instance. It is possible that a woman may value two complementary dresses more because she can choose between them and combine each with different shoes, clothes and jewellery, so that she seems to have an extensive wardrobe (Gabszewicz, Sonnac and Wauthy, 2001). Thus, a monopolist can take this into account when it comes to designing a product line. As we can note in previous examples, complementarity can be seen as a source of horizontal differentiation.

We focus on markets for information goods. As in Varian (2001a) we take information goods to be anything that can be digitized - for instance books, movies, music, journals, software, games, databases, telephone conversations, stock quotes, web pages, news, ring tones ... (Varian, 2001a, and Belleflamme, 2005). These goods are characterized by larger fixed costs of production and small variable costs of reproduction (Varian, 2001b). Thus, they must be priced according to the value consumers attach to them, not according to its production cost (Varian, 2001b, and Belleflamme, 2005).

Versioning goods (or equivalently second degree price discrimination) have previously been analysed from a theoretical viewpoint. In a seminal 1979 paper, Stokey provides conditions under which (second degree) price discrimination is not optimal. In a later study Salant (1989) shows that price discrimination is not optimal if the marginal cost function of improving quality is linear. However, under these conditions, Jing (2007) shows that the presence of network externalities restores the optimality of price discrimination (or versioning goods). ${ }^{2}$

A related paper is written Calzada and Valletti (2012). They study a model of film distribution and consumption in which the studio can release two products (a theatrical version and a video version) and some consumers may watch both versions. They focus on the timing of the firms' strategy. They find that the simultaneous release of the versions can be optimal when the studio is integrated with the exhibition and distribution channels.

$1 \quad$ For an analysis of versioning goods in Software industry see Shivendu and Zhang (2012). This paper does not allow consumers to buy versions simultaneously.

2 See Wei and Nault (2014) for a model that considers groups of consumers that share the same group taste. 
A special strategy of versioning goods consists of damaging a high-quality product because this is a cheaper way of producing a low-quality product than actually making a low-quality product. This particular strategy has been analysed by Deneckere and McAfee (1996), who provide many examples of it in the chemicals, electronics and pharmaceutical industries, and show that it can be profitable for a firm and a Pareto improvement.

In a recent paper Bhargava and Choudhary (2008) show that if the marginal cost of manufacturing is invariant in quality, versioning is optimal when the optimal market share of the lower-quality version offered alone is greater than the optimal market share of the high-quality version offered alone.

These papers fail to take into account that consumers may simultaneously buy low- and high-quality versions of a product. This has been analysed in a duopoly model of vertical differentiation by Gabszewicz, Sonnac and Wauthy (2001) for complementary variants and by Gabszewicz and Wauthy (2003) for substitutes. These authors call this possibility a joint purchase option.

We develop a monopoly model of vertical product differentiation for analysing the monopolist's decision about the possibility of versioning goods as substitutes or complements when the joint purchase option is available to consumers. ${ }^{3}$ In this context, we find that versioning goods as substitutes or complements is optimal for the monopolist if the cost of improving the quality of the bundle (the purchase of one unit of each version) is increasing, which implies that making variants of closer substitutes reduces costs. However, if making variants of more substitutes is costly, the monopolist versions goods as complements only. The final result also depends on the degree of concavity and convexity of the cost function.

The rest of the paper is organized as follows. Section 2 describes the model formally. The monopolist's decision about how to design different variants of a product is analysed in Section 3. Section 4 analyses equilibrium strategies. Section 5 analyses monopolist's decision when making variants closer substitutes is costly and Section 6 concludes.

\section{The Model}

We consider a monopolist who decides whether to produce one or two variants of a product. The two variants are vertically differentiated as per Mussa and Rosen (1978), so there is a variant of high quality, indexed by $u_{h}$, and other of low quality, indexed by $u_{l}$. Thus, $u_{h}>u_{l}$. We assume that the monopolist produces at zero cost. He chooses the prices of the variants and the degree of substitution and complementarity between them so as to maximize profits.

Unlike previous models that analyse versioning strategies, in this paper we allow consumers to simultaneously buy the two variants of a product. This possibility can be viewed as consuming a third variant of quality $u_{2}$. Consumers are indexed by $\theta \in[0,1]$ which represents consumers' tastes for the quality of a product. We assume that $\theta$ follows a uniform distribution. The utility of consumer $\theta$ is

$$
U\left(\theta, u_{l}, u_{h}, u_{2}, p_{l}, p_{h}\right)=\left\{\begin{array}{cl}
\theta u_{2}-p_{h}-p_{l} & \text { if he/she buys both variants (or the "bundle") } \\
\theta u_{h}-p_{h} & \text { if he/she buys the hugh-quality variant } \\
\theta u_{l}-p_{l} & \text { if he/she buys the low-quality variant } \\
0 & \text { if he/she does not buy }
\end{array}\right.
$$

3 This model is related with those that analyse the multiproduct pricing problem. For a dynamic perspective see Akcay et al. (2010). 
where $p_{l}$ and $p_{h}$ are the price of the low- and high-quality variants, respectively. In order to find the monopolist's demand function, we consider two cases: (i) $u_{2} \in\left(u_{h}, u_{l}+u_{h}\right)$ if the two variants are substitutes, and (ii) $u_{2} \in\left[u_{l}+u_{h},+\infty\left[\right.\right.$ if they are complementary. ${ }^{4}$

(i) Substitutes $\left(u_{2} \in\left(u_{h}, u_{l}+u_{h}\right)\right)$

Let $\theta_{l}$ be a consumer indifferent between buying the low-quality variant and not buying at all, from function (1), $\theta_{l}=p_{l} / u_{l}$. Let $\theta_{h}$ be a consumer indifferent between buying the high-quality variant and not buying at all, that is, $\theta_{h}=p_{h} / u_{h}$. Let $\theta_{2}$ be a consumer indifferent between buying the bundle and not buying at all, that is, $\theta_{2}=\left(p_{1}+p_{h}\right) / u_{2}$. Let $\theta_{h l}$ be a consumer indifferent between buying the high and low-quality variants, that is, $\theta_{h l}=\left(p_{h}-p_{l}\right) /\left(u_{h}-u_{l}\right)$. Let $\theta_{2 l}$ be a consumer indifferent between buying the low-quality variant and one unit of both variants (bundle), that is, $\theta_{2 l}=p_{h} /\left(u_{2}-u_{1}\right)$. Let $\theta_{2 h}$ be a consumer indifferent between buying the high-quality variant and one unit of both variants (bundle), that is, $\theta_{2 h}=p_{l} /\left(u_{2}-u_{h}\right)$.

From these definitions, we derive the monopolist's demand functions for each variant. But first we identify the critical regions of the domain of $\left(p_{l}, p_{h}\right)$-prices, which are shown in Figure 1(a) and coincide with those computed by Gabszewicz and Wauthy (2003). The region (or subdomain) $P_{l}$ is defined as

$$
P_{1}=\left\{\left(p_{l}, p_{h}\right): p_{l} \geq u_{2}-u_{h}\right\}
$$

In this region the consumer who is most willing to pay to consume both variants $(\theta=1)$ prefers the high-quality variant alone to buying them at that prices because $p_{l}$ is too high. Thus, the demand function of each variant is the same one that we obtain in a model of vertical differentiation in which buying the bundle is not possible, so the demand functions are as follows:

$$
D_{l}\left(p_{l}, p_{h}\right)=\theta_{h l}-\theta_{l} ; \quad D_{h}\left(p_{l}, p_{h}\right)=1-\theta_{h l} .
$$

Region $P_{2}$ is defined by

so

$$
P_{2}=\left\{\left(p_{l}, p_{h}\right): p_{l}<u_{2}-u_{h} ; p_{l} \geq p_{h} \frac{u_{l}}{u_{h}}\right\},
$$

$$
\theta_{h l} \leq \theta_{h} \leq \min \left\{\theta_{l}, \theta_{2 l}\right\} \leq \max \left\{\theta_{l}, \theta_{2 l}\right\}<\theta_{2 h} .
$$

Thus, the demands are as follows ${ }^{5}$

$$
D_{l}\left(p_{l}, p_{h}\right)=1-\theta_{2 h} ; D_{h}\left(p_{l}, p_{h}\right)=1-\theta_{h} .
$$

Notice that in $P_{2}$ all consumers who buy the low-quality variant also buy the high-quality variant, so there are some consumers who only buy variant $h$. Thus the demand for variant $h$ coincides with the monopoly's demand when it is offered alone. Region $P_{3}$ is defined as follows

$4 \quad$ See Gabszewicz, Sonnac and Wauthy (2001) and Gabszewicz and Wauthy (2003) for a detailed analysis of demand functions of complementary and substitute variants of the same product in a duopoly model of vertical differentiation, respectively.

5 Notice that $\theta_{2}>\theta_{h}$. 


$$
\begin{gathered}
P_{3}=\left\{\left(p_{l}, p_{h}\right): p_{l}<u_{2}-u_{h} ; p_{h} \frac{u_{2}-u_{h}}{u_{2}-u_{l}} \leq p_{l} \leq p_{h} \frac{u_{l}}{u_{h}}\right\}, \\
\text { so } \theta_{l} \leq \theta_{h} \leq \theta_{h l} \leq \theta_{2 l} \leq \theta_{2 h} .
\end{gathered}
$$

Thus, the demand functions are as follows ${ }^{6}$

$$
D_{l}\left(p_{l}, p_{h}\right)=1-\theta_{2 h}+\theta_{h l}-\theta_{l}=1+\frac{p_{h}}{u_{h}-u_{l}}-p_{l} K ; D_{h}\left(p_{l}, p_{h}\right)=1-\theta_{h l},
$$

where

$$
K=\frac{u_{l}\left(u_{2}-u_{l}\right)+\left(u_{h}-u_{l}\right)\left(u_{2}-u_{h}\right)}{u_{l}\left(u_{h}-u_{l}\right)\left(u_{2}-u_{h}\right)} .
$$

In this region, there are consumers who only buy the low- or high-quality variant. Finally, region $P_{4}$, which is symmetric to $P_{2}$, is defined as follows

$$
\begin{aligned}
& P_{4}=\left\{\left(p_{l}, p_{h}\right): p_{l}<u_{2}-u_{h} ; p_{l} \leq p_{h} \frac{u_{2}-u_{h}}{u_{2}-u_{l}}\right\}, \\
& \text { so } \theta_{l}<\min \left\{\theta_{2 h}, \theta_{h}\right\} \leq \max \left\{\theta_{2 h}, \theta_{h}\right\} \leq \theta_{2 l} \leq \theta_{h l} .
\end{aligned}
$$

Thus, the demand functions are as follows ${ }^{7}$

$$
D_{l}\left(p_{l}, p_{h}\right)=1-\theta_{l} ; D_{h}\left(p_{l}, p_{h}\right)=1-\theta_{2 l} .
$$

Contrary to $P_{2}$, in this region there are some consumers who only buy low quality variant.

Figure 1 | Partition of the Price Region

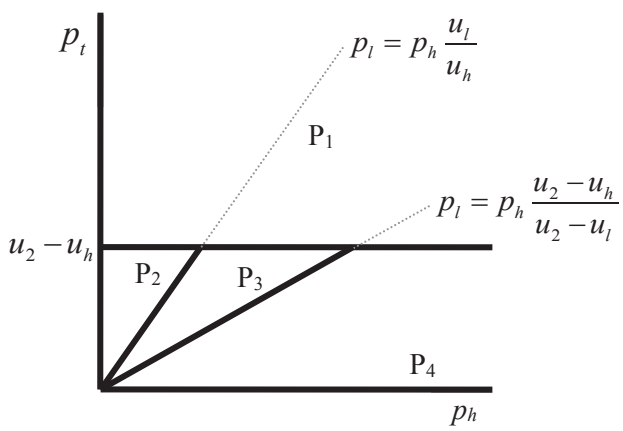

(a) $u_{2} \in\left(u_{h}, u_{l}+u_{h}\right)$

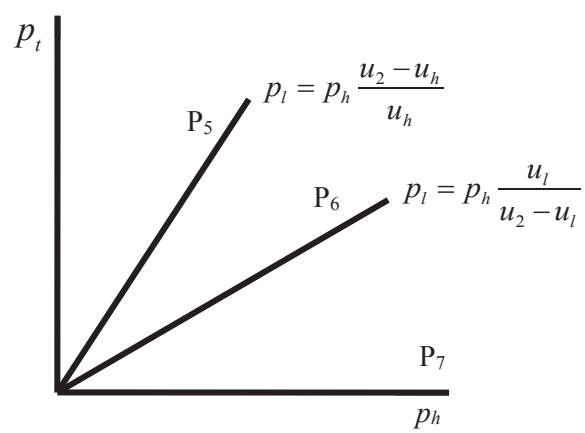

(a) $u_{2} \in\left[u_{l}+u_{h},+\infty[\right.$

(ii) Complementary variants $\left(\boldsymbol{u}_{2} \in\left[\boldsymbol{u}_{l}+\boldsymbol{u}_{h},+\infty[)\right.\right.$

We now describe the monopolist's demand function when the two variants are complementary. Thus, we take into account only the indifferent consumers $\theta_{l}, \theta_{h}$ and $\theta_{2}$, described above. Three critical regions of the domain of $\left(p_{l}, p_{h}\right)$-prices are identified, which are shown

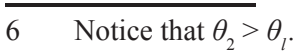

7 Notice that $\theta_{2}>\theta_{l}$. 
in Figure 1(b) and coincide with those computed by Gabszewicz, Sonnac and Wauthy (2001). The region (or subdomain) $P_{5}$ is defined as follows

so

$$
P_{5}=\left\{\left(p_{l}, p_{h}\right): p_{l} \geq p_{h} \frac{u_{2}-u_{h}}{u_{h}}\right\},
$$

$$
\theta_{h} \leq \theta_{2} \leq \theta_{l} .
$$

Thus, the demand for each variant is as follows

$$
D_{l}\left(p_{l}, p_{h}\right)=1-\theta_{2} ; D_{h}\left(p_{l}, p_{h}\right)=1-\theta_{h} .
$$

As in $P_{2}$, there are some consumers who only buy high-quality variant. The region $P_{6}$ is as follows

so

$$
P_{6}=\left\{\left(p_{l}, p_{h}\right): p_{h} \frac{u_{l}}{u_{2}-u_{l}} \leq p_{l} \leq p_{h} \frac{u_{2}-u_{h}}{u_{h}}\right\},
$$

$$
\theta_{2} \leq \min \left\{\theta_{l}, \theta_{h}\right\} .
$$

Thus, the demand for each variant is as follows

$$
D_{l}\left(p_{l}, p_{h}\right)=D_{h}\left(p_{l}, p_{h}\right)=1-\theta_{2} .
$$

In this region, firms' demand coincides with the demand for the bundle (the purchase of the two variants). Finally, region $P_{7}$ is symmetric to region $P_{5}$, so it is described as follows

so

$$
P_{7}=\left\{\left(p_{l}, p_{h}\right): p_{l} \leq p_{h} \frac{u_{l}}{u_{2}-u_{l}}\right\},
$$

$$
\theta_{l} \leq \theta_{2} \leq \theta_{h} \text {. }
$$

Thus, the demand for each variant is as follows

$$
D_{l}\left(p_{l}, p_{h}\right)=1-\theta_{l} ; D_{h}\left(p_{l}, p_{h}\right)=1-\theta_{2} .
$$

As in $P_{4}$, all consumers who buy the high-quality variant also buy the low-quality variant. The monopolist's profit is as follows

$$
\pi\left(u_{l}, u_{h}, u_{2}, p_{l}, p_{h}\right)=p_{l} D_{l}\left(p_{l}, p_{h}\right)+p_{h} D_{h}\left(p_{l}, p_{h}\right)-C\left(u_{2}\right)
$$

where $D_{l}($.$) and D_{h}($.$) represent the demand for the low- and high-quality variants,$ respectively, and $C\left(u_{2}\right)$ represents the fixed cost of improving the quality of the bundle, which is increasing, i.e. $C^{\prime}\left(u_{2}\right)>0 .^{8}$ Therefore, making variants of less close substitutes or more complementary ones is costly, so making the variant closer substitutes reduces cost. It is because a lower (higher) $u_{2}$ implies that variants are closer substitutes (more complementary). Intuitively, improving the quality of the bundle (variants less substitutes or more complementary) requires an innovation design which is costly. Given that we analyse markets for information goods, we consider that the marginal cost of production is equal to zero.

8 This cost function is in line with the cost function of quality improvement considered by Motta (1993). 
The timing of the complete information game is as follows. First, the monopolist decides the relationship between the high- and low-quality variants, i.e. it decides the values of $u_{2}$. Next it sets the price of each variant. Finally, consumers decide to buy the high-quality variant, the low-quality variant, the bundle or neither after they have observed the prices of the variants.

In the next section, we look for the subgame perfect equilibrium (SPE) by backward induction. Thus, we first look for the optimal prices and then the optimal design of both versions.

\section{Equilibrium}

In this section, we seek to find the monopolist's equilibrium strategy, which consists of a choice about the degree of relationship between the high- and low-quality variants (substitutes or complements) and about the prices of the variants. To that end, in the next two subsections we look for the optimal price strategy when the two variants are substitutes and complements, respectively. Then we seek the optimal degree of relationship between them.

\subsection{Substitution}

We now obtain the optimal price strategy for the regions $P_{1}, P_{2}, P_{3}$ and $P_{4}$, as described above. The monopolist, in region $P_{3}$, faces the demand (5), so that by maximizing the monopolist's profit function (11), we have that the optimal prices, demand and profit are:

$$
\begin{gathered}
\bar{p}_{3}^{*}=\left(p_{l}, p_{h}\right)=\left(\frac{u_{l}\left(u_{2}-u_{h}\right)}{u_{2}+u_{l}-u_{h}}, \frac{u_{l}\left(u_{2}-u_{l}\right)+u_{h}\left(u_{2}-u_{h}\right)}{2\left(u_{2}+u_{l}-u_{h}\right)}\right) ; \\
D_{l}^{* 3}=D_{h}^{* 3}=\frac{1}{2} ; \quad \pi^{* 3}=\frac{u_{2}\left(u_{h}+3 u_{l}\right)-\left(u_{l}+u_{h}\right)^{2}}{4\left(u_{2}+u_{l}-u_{h}\right)} .
\end{gathered}
$$

Notice that $\bar{p}_{3}^{*} \in P_{3}$ and the market is not completely covered. The demand functions that the monopolist faces in region $P_{2}$ are (3), so that the optimal prices are $\bar{p}_{2}^{*}=\left(p_{l}, p_{h}\right)=\left(\left(u_{2}-u_{h}\right) / 2, u_{h} / 2\right)$. Notice that $\bar{p}_{2}^{*} \notin P_{2}$, so the best strategy lies at the frontier with $P_{3}$, which by continuity is itself dominated by the best strategy in the interior of $P_{3}$. Thus, the optimal strategy is not in region $P_{2}$. Given that region $P_{4}$ is symmetric to region $P_{2}$, we obtain that nor is the optimal strategy in region $P_{4}$.

In region $P_{1}$, the monopolist faces the demand functions (2), so we have that optimal prices, demands and profit are:

$$
\bar{p}_{1}^{*}=\left(p_{l}, p_{h}\right)=\left(\frac{u_{l}}{2}, \frac{u_{h}}{2}\right) ; \quad D_{l}^{* 1}=0 ; \quad D_{h}^{* 1}=\frac{1}{2} ; \quad \pi^{* 1}=\frac{u_{h}}{4} ;
$$

Notice that $\bar{p}_{1}^{*} \in P_{1}$ if $u_{2} \leq u_{h}+u_{l} / 2$, otherwise $\bar{p}_{1}^{*} \notin P_{1}$. So in the last case the best strategy lies at the frontier with $P_{2}, P_{3}$ and $P_{4}$, which by continuity and the result obtained before is itself dominated by the best strategy in the interior of $P_{3}$. Therefore, the optimal price strategy is in region $P_{3}$ if $u_{2} \geq u_{h}+u_{l} / 2$.

Nevertheless, when $u_{2} \leq u_{h}+u_{l} / 2$, the optimal price strategy is in regions $P_{1}$ or $P_{3}$. By comparing $\pi^{* 1}$ and $\pi^{* 3}$ we get the optimal strategy for the monopolist, which is $\bar{p}_{1}^{*}$ if $u_{2} \leq u_{h}+u_{l} / 3$, otherwise it is $\bar{p}_{3}^{*}$. This means that versioning products as substitutes are not 
optimal when they are very close substitutes, i.e. when the utility associated with the joint purchase option is low enough. These results are summarized in the following proposition.

Proposition 1 If the two variants are substitutes and consumers can buy them simultaneously, the monopolist decides to sell both at prices

$$
p_{s}^{*}= \begin{cases}\bar{p}_{1}^{*} & \text { if } u_{2} \leq u_{h}+u_{l} / 3 \\ \bar{p}_{3}^{*} & \text { if } u_{2} \geq u_{h}+u_{l} / 3\end{cases}
$$

From Proposition 1, we observe that the monopolist versions a product if $u_{2}$ is high enough. Otherwise it does not offer consumers a low-quality variant. In other words, the optimal strategy for the monopolist is to sell the high-quality variant only if $u_{2}$ is low enough. This result is keeping with the standard result obtained by the previous studies of versioning goods or second-degree price discrimination (Stokey, 1979, and Salant, 1989).

\subsection{Complementarity}

In this subsection, we consider that variants are complementary, so the partition of the domain of prices is as drawn in Figure 1(b). In region $P_{5}$, the monopolist's demand functions are (8), so the optimal prices, demands and profit are:

$$
\bar{p}_{5}^{*}=\left(\frac{u_{2}\left(2 u_{2}-u_{h}\right)}{4 u_{2}-u_{h}}, \frac{u_{2} u_{h}}{4 u_{2}-u_{h}}\right) ; \quad D_{l}^{* 5}=\frac{2 u_{2}-u_{h}}{4 u_{2}-u_{h}} ; \quad D_{h}^{* 5}=\frac{3 u_{2}-u_{h}}{4 u_{2}-u_{h}} ; \quad \pi^{* 5}=\frac{u_{2}^{2}}{4 u_{2}-u_{h}} .
$$

Notice that $\bar{p}_{5}^{*} \in P_{5}$. The demands that the monopolist faces in region $P_{6}$ are (9). Since the bundle is considered as a third good, the firm behaves as a monopolist that only sells that product, so that the optimal prices $\bar{p}_{6}^{*}$ are those such that $p_{l}^{*}+p_{h}^{*}=p_{2}^{*}=\frac{u_{2}}{2}$ and $\bar{p}_{6}^{*} \in P_{6}$. Thus, the demand and profit correspond to those in a monopoly, i.e. $D_{2}^{* 6}=1 / 2$ and $\pi^{* 6}=u_{2} / 4$. Finally, we consider region $P_{7}$, in which the monopolist's demands are (10), so the optimal prices, demands and profit are:

$$
\bar{p}_{7}^{*}=\left(\frac{u_{2} u_{l}}{4 u_{2}-u_{l}}, \frac{u_{2}\left(2 u_{2}-u_{l}\right)}{4 u_{2}-u_{l}}\right) ; D_{l}^{* 7}=\frac{3 u_{2}-u_{l}}{4 u_{2}-u_{l}} ; \quad D_{h}^{* 7}=\frac{2 u_{2}-u_{l}}{4 u_{2}-u_{l}} ; \quad \pi^{* 7}=\frac{u_{2}^{2}}{4 u_{2}-u_{l}} .
$$

Notice that $\bar{p}_{7}^{*} \in P_{7}$. By comparing the profits obtained in regions $P_{5}, P_{6}$ and $P_{7}$, we have $\pi^{* 6}<\pi^{* 7}<\pi^{* 5}$. Thus, when variants are complementary and consumers can simultaneously buy both variants, the monopolist's optimal price is $p^{* 5}$, which means that versioning products are also optimal in this case. This result is shown in Proposition 2.

Proposition 2 If the two variants are complementary and consumers can buy them simultaneously, the monopolist sells both at prices $p_{c}^{*}=\bar{p}_{5}^{*}$.

\subsection{Substitute or complementary variants}

In this subsection, taking into account the previous results, we seek to establish the monopolist's optimal choice about the degree of substitution or complementarity. The monopolist faces the following profit function: ${ }^{9}$

9 We look for only interior solutions. Notice that this function is discontinuous at $u_{2}=u_{l}+u_{h}$. This point represents the border in which the two variants are complementary $\left(u_{2} \in\left[u_{l}+u_{h},+\infty[)\right.\right.$, but not substitutes $\left(u_{2} \in\left(u_{h}, u_{l}+u_{h}\right)\right)$. 


$$
\pi\left(p_{l}, p_{h}\right)=\left\{\begin{array}{cc}
\frac{u_{h}}{4}-C\left(u_{2}\right) & \text { if } u_{h}<u_{2} \leq u_{h}+u_{l} / 3 ; \\
\frac{u_{2}\left(u_{h}+3 u_{l}\right)-\left(u_{h}+u_{l}\right)^{2}}{4\left(u_{2}+u_{l}-u_{h}\right)}-C\left(u_{2}\right) & \text { if } u_{h}+u_{l} / 3 \leq u_{2}<u_{l}+u_{h} ; \text { and } \\
\frac{u_{2}^{2}}{4 u_{2}-u_{h}}-C\left(u_{2}\right) & \text { if } u_{2} \geq u_{l}+u_{h} .
\end{array}\right.
$$

By maximizing this profit function on $u_{2}$, we find the equilibrium degree of substitution or complementarity. In particular, we find two equilibrium candidates: one where the two variants are substitutes $\left(u_{2}^{s}\right)$ and another where they are complementary $\left(u_{2}^{c}\right)$. Given the assumptions in the model developed here, we cannot obtain the explicit expression of $u_{2}$, but we can provide conditions that allow us to select the equilibrium. Namely, as we show in Proposition 3, when the cost function of improving the quality of the bundle is slightly concave or convex, the only equilibrium possible is for the two variants to be substitutes; and if the cost function is convex enough, the two candidates are equilibrium. This result is because of versioning the two variants as complements is profitable if the cost function is convex enough, while versioning them as substitutes is profitable if the cost function is convex or slightly concave. ${ }^{10}$

Proposition 3 When a monopolist can version substitute/complementary products, the joint purchase option is available to consumers and improving the quality of the bundle is costly, we have that

a) if $C^{\prime \prime}\left(u_{2}\right) \in\left[-\infty,-\frac{2 u_{l}^{2}}{\left(u_{2}+u_{l}-u_{h}\right)^{3}}\right]$, there is no equilibrium;

b) if $C^{\prime \prime}\left(u_{2}\right) \in\left[-\frac{2 u_{l}^{2}}{\left(u_{2}+u_{l}-u_{h}\right)^{3}}, \frac{2 u_{h}^{2}}{\left(4 u_{2}-u_{h}\right)^{3}}\right]$, the only equilibrium is $u_{2}^{*}=u_{2}^{s}$;

c) otherwise, $u_{2}^{s:}$ and $u_{2}^{c}$ can be an equilibrium.

Proof of Proposition 3 We maximize the profit function (16), so the first order condition (FOC) is:

$$
\frac{\partial \pi\left(p_{l}, p_{h}\right)}{\partial u_{2}}=\left\{\begin{array}{cc}
-C^{\prime}\left(u_{2}\right)=0 & \text { if } u_{h}<u_{2} \leq u_{h}+u_{l} / 3 ; \\
\frac{u_{l}^{2}}{\left(u_{2}+u_{l}-u_{h}\right)^{2}}-C^{\prime}\left(u_{2}\right)=0 & \text { if } u_{h}+u_{l} / 3 \leq u_{2}<u_{l}+u_{h} ; \text { and } \\
\frac{2 u_{2}\left(2 u_{2}-u_{h}\right)}{\left(4 u_{2}-u_{h}\right)^{2}}-C^{\prime}\left(u_{2}\right)=0 & \text { if } u_{2} \geq u_{l}+u_{h} .
\end{array}\right.
$$

10 As noted by the referee, if the cost function of improving the quality of the bundle is linear, the only equilibrium is to make the two variant substitutes. 
From the FOC, given that $C^{\prime}\left(u_{2}\right)>0$, we find the implicit expressions that define the equilibrium degrees of substitution and complementarity and that $u_{2}^{s} \in\left[u_{h}+u_{l} / 3, u_{l}+u_{h}[\right.$. The second order condition SOC is:

$$
\frac{\partial \pi^{2}\left(p_{l}, p_{h}\right)}{\partial^{2} u_{2}}=\left\{\begin{array}{cc}
-C^{\prime \prime}\left(u_{2}\right) \leq 0 & \text { if } u_{h}<u_{2} \leq u_{h}+u_{l} / 3 ; \\
-\frac{2 u_{l}^{2}}{\left(u_{2}+u_{l}-u_{h}\right)^{3}}-C^{\prime \prime}\left(u_{2}\right) \leq 0 & \text { if } u_{h}+u_{l} / 3 \leq u_{2}<u_{l}+u_{h} ; \text { and } \\
\frac{2 u_{h}^{2}}{\left(4 u_{2}-u_{h}\right)^{3}}-C^{\prime \prime}\left(u_{2}\right) \leq 0 & \text { if } u_{2} \geq u_{l}+u_{h} .
\end{array}\right.
$$

We can easily check that,

1) if $C^{\prime \prime}\left(u_{2}\right) \in\left[-\infty,-\frac{2 u_{l}^{2}}{\left(u_{2}+u_{l}-u_{h}\right)^{3}}\right)$, there is no equilibrium;

2) if $C^{\prime \prime}\left(u_{2}\right) \in\left[-\frac{2 u_{l}^{2}}{\left(u_{2}+u_{l}-u_{h}\right)^{3}}, \frac{2 u_{h}^{2}}{\left(4 u_{2}-u_{h}\right)^{3}}\right]$, the only equilibrium candidate that satisfies
SOC is $u_{2}^{s^{3}}$;

3) otherwise, the two candidates satisfy SOC, so that $u_{2}^{s i}$ and $u_{2}^{c}$ can be an equilibrium.

\section{Analysis of Equilibrium}

By comparing the equilibrium demands when the two variants are substitutes with those when they are complementary, we have

$$
D_{l}^{c}<D_{l}^{s}=D_{h}^{s}<D_{h}^{c},
$$

where superscripts $s$ and $c$ represent the equilibrium when the variants are substitutes and complements, respectively. From (19), we observe that the monopolist sells the low-quality variant more when it is a substitute for the high-quality variant. Moreover, when both variants are substitutes, the demand for them is the same.

Let $\theta_{h}^{1}=1 / 2$ be a consumer indifferent between buying the high-quality variant and not buying at all when the monopolist decides to offer the high-quality variant only in equilibrium. From relationship (4) and the equilibrium results when variants are substitutes on (12), we have

$$
\theta_{l}^{s}<\theta_{h}^{1}=\theta_{h l}^{s}<\theta_{2 h}^{s} .
$$

In the same way, from relationship (7) and the equilibrium results when variants are complementary on (14), we have

$$
\theta_{h}^{c}<\theta_{h}^{l}<\theta_{2}^{c}<\theta_{l}^{s} .
$$

Therefore, from relationships (20) and (21), we show that there is no cannibalization effect. ${ }^{11}$ This explains why versioning substitute/complementary goods is optimal when the joint purchase option is available to consumers. This last result is summarized in Proposition 4 and illustrated in Figure 2 on the next page.

11 The cannibalization effect represents the fact that there are consumers who would buy the highquality variant if it was the only one available, but who would buy the low-quality variant otherwise. 
Proposition 4 If a monopolist can version substitute/complementary products and consumers can simultaneously buy the two versions, there is no cannibalization effect.

Figure 2 | Effect of Versioning Substitute-Complementary Products

(a) Substitute variants

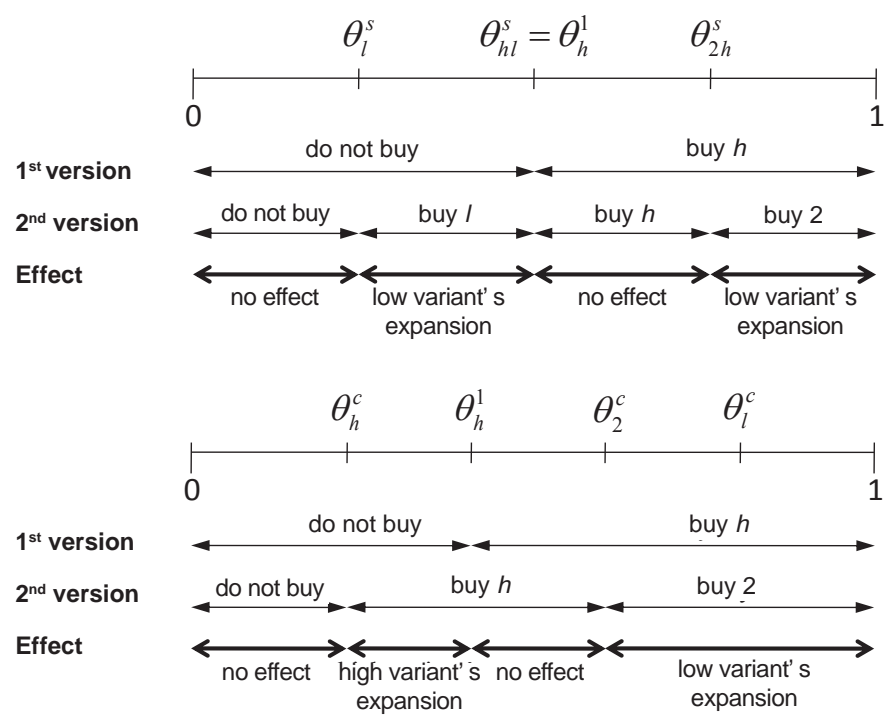

As can be seen from Figure 2, the expansion effect is felt only in variant $l$ when the two variants are substitutes, but if they are complementary, the expansion effect is felt in both the low- and high-quality variants.

Let $u_{2}^{s *}$ and $u_{2}^{c *}$ be the equilibrium degree of substitution and complementarity, respectively. Since we do not know the explicit expression of $u_{2}^{s *}$ and $u_{2}^{c *}$, we cannot make a complete analysis of equilibrium, but we can find how these equilibria change as the two variants differ more in quality. Notice that a higher $u_{2}^{s *}$ implies that variants are less close substitutes, and a higher $u_{2}^{c *}$ implies that they are more complementary. Through the theorem of implicit function, we obtain that a higher quality of the high-quality variant implies, ceteris paribus (which is equivalent to a higher differentiation), that variants are less close substitutes and less complementary. Intuitively, this means that when the differentiation between variants increases, the monopolist will seek to boost joint purchase if variants are substitutes, and seek to save costs if variants are complementary. The result is shown in the following proposition.

Proposition $5 \mathrm{~A}$ higher differentiation implies lower substitution if variants are substitutes, and lower complementarity if they are complementary.

Proof of Proposition 5 Let

$$
\begin{aligned}
& F\left(u_{l}, u_{h}, u_{2}\right)=\frac{u_{l}^{2}}{\left(u_{2}+u_{l}-u_{h}\right)^{2}}-C^{\prime}\left(u_{2}\right), \text { and } \\
& G\left(u_{l}, u_{h}, u_{2}\right)=\frac{2 u_{2}\left(2 u_{2}-u_{h}\right)}{\left(4 u_{2}-u_{h}\right)^{2}}-C^{\prime}\left(u_{2}\right) .
\end{aligned}
$$


From the theorem of implicit function and the results obtained from the Proof of Proposition 3 , we have

$$
\begin{aligned}
& \frac{d u_{2}^{s *}}{d u_{h}}=-\frac{F_{u_{h}}}{F_{u_{2}}}=\frac{\frac{2 u_{l}^{2}}{\left(u_{2}+u_{l}-u_{h}\right)^{3}}}{\frac{2 u_{l}^{2}}{\left(u_{2}+u_{l}-u_{h}\right)^{3}}+C^{\prime \prime}\left(u_{2}\right)}>0, \text { and } \\
& \frac{d u_{2}^{c *}}{d u_{h}}=-\frac{G_{u_{h}}}{G_{u_{2}}}=\frac{\frac{2 u_{h}}{\left(4 u_{2}-u_{h}\right)^{3}}}{\frac{2 u_{h}^{2}}{\left(4 u_{2}-u_{h}\right)^{3}}-C^{\prime \prime}\left(u_{2}\right)}<0 .
\end{aligned}
$$

Notice that when the monopolist decides on the utility level of the joint purchase option, it compares the profits and costs from encouraging joint purchase and decreasing competition (a higher $u_{2}$ ) with those obtained by saving costs and increasing competition (a lower $u_{2}$ ).

\section{When Making Variants Substitute Is Costly}

So far we have assumed that improving the quality of the bundle is costly, which implies that making variants of closer substitutes reduces costs. However, it could be costly. In this section we analyse that situations in which making variants of more substitutes or more complementary products is costly. Thus, we assume that the fixed cost of designing the bundle, $C\left(u_{2}\right)$, is decreasing if $u_{2}<u_{l}+u_{h}$, and increasing if $u_{2} \geq u_{l}+u_{h}$. In this case, as we show in Proposition 6, the monopolist versions goods as complements only if the fixed cost of designing the bundle is convex enough. This result is because the cost of designing the bundle is decreasing when the two variants are substitutes.

Proposition 6 When a monopolist can version substitute/complementary goods, the joint purchase option is available to consumers, making variant closer substitutes or more complementary is costly and the fixed cost function of designing the bundle is convex enough, the monopolist versions goods as complements only.

Proof of Proposition 6 We maximize the profit function (16) and find the first order condition (17). Given the shape of the fixed cost of designing the bundle, we find that the only equilibrium candidate that satisfies FOC is $u_{2}^{c^{s}}$. From the SOC (18), we have that $u_{2}^{c^{\prime}}$ is an equilibrium if

$$
C^{\prime \prime}\left(u_{2}\right) \in\left[\frac{2 u_{h}^{2}}{\left(4 u_{2}-u_{h}\right)^{3}},+\infty\right) \text {. }
$$

\section{Conclusions}

We analyse the monopolist's decision about how to design different versions of a product, i.e. whether it decides to make them as substitutes or complements, when consumers can buy them simultaneously. The framework of analysis used is a monopoly model with vertical differentiation, where the monopolist also sets prices.

We find that, if the cost of designing the bundle is increasing, versioning goods as substitutes or complements is optimal for the monopolist because this strategy eliminates the cannibalization effect. Moreover, when the cost function is slightly concave or convex, 
the only equilibrium is when the two variants are substitutes; and if the cost function is convex enough, there are two equilibriums: one where the two variants are substitutes and another where they are complementary. It is because an increasing cost of improving the quality of the bundle implies that making variants which are closer substitutes reduces costs. However, if making variant closer substitutes or more complementary is costly and the fixed cost function of designing the bundle is convex enough, the monopolist versions goods as complements only.

Another result is that if variants are very close substitutes, the monopolist offers the high-quality variant only. In other words, he decides to not create a low-quality variant of an existing product if it is a close substitute for the high-quality variant. Otherwise, versioning product is optimal, independently of whether variants are substitutes or complements. Therefore, the optimality of versioning goods depends on the degree of substitution and complementarity and the possibility of buying the two variants at the same time.

We also show that when the differentiation between variants increases, the monopolist seeks to boost joint purchase if variants are substitutes, and to save costs if variants are complementary.

The results obtained in this paper show that it is possible to make the versioning goods strategy profitable when we take into account that versions can be complementary or substitute and consumers can buy them simultaneously. For instance, it could be the case in film industry when it designs different versions of a movie. Finally, we obtain that versioning goods is profitable for the monopolist for a simple price strategy, but it could be more profitable for complex price strategies.

\section{References}

Akcay, Y., H. P. Natarajan and S. H. Xu (2010). Joint Dynamic Pricing of Multiple Perishable Products under Consumer Choice. Management Science, 56 (8), 1345-1361. DOI: $10.1287 / \mathrm{mnsc} .1100 .1178$.

Belleflamme, P. (2005). Versioning in the Information Economy: Theory and Applications. CESifo Economic Studies, 51 (2-3), 329-358. DOI: 10.1093/cesifo/51.2-3.329.

Bhargava, H. K., Choudhary V. (2008). Research Note: When Is Versioning Optimal for Information Goods? Management Science, 54 (5), pp. 1029-1035.

DOI: $10.1287 / \mathrm{mnsc}$.1070.0773.

Calzada, J. and T. Valletti (2012). Intertemporal Movie Distribution: Versioning When Customers Can Buy Both Versions. Marketing Science, 31(4), 649-667. DOI: 10.1287/mksc.1120.0716.

Deneckere, R. J., McAfee, R. P. (1996). Damaged Goods. Journal of Economics and Management Strategy, 5 (2), 149-174.

Gabszewicz, J. J., Sonnac, N., Wauthy X. (2001). On Price Competition with Complementary Goods. Economics Letters, 70(3), 431-437. DOI:10.1016/S0165-1765(00)00383-9.

Gabszewicz, J. J., Wauthy X. (2003). The Option of Joint Purchase in Vertically Differentiated Markets. Economic Theory, 22(4), 817-829. DOI:10.1007/s00199-003-0359-2.

Jing, B., (2007). Network Externality and Market Segmentation in a Monopoly. Economics Letter, 95(1), 7-13. DOI:10.1016/j.econlet.2006.08.033.

Motta, M., (1993). Endogenous Quality Choice: Price vs. Quantity Competition. The Journal of Industrial Economics, 41(2), 113-131. DOI: 10.2307/2950431 
Mussa, M., Rosen, S. (1978). Monopoly and Product Quality. Journal of Economic Theory, 18(2), 301-317. DOI: 10.1016/0022-0531(78)90085-6.

Nalebuff, B., Ayres, I. (2003). Why Not? How to Use Everyday Ingenuity to Solve Problems Big and Small, Harvard Business School Press.

Salant, S.W. (1989). When Is Inducing Self-Selection Suboptimal for a Monopolist? Quaterly Journal of Economics, 104 (2), 391-397. DOI: 10.2307/2937854.

Shivendu, S. and Z. Zhang, (2012). Vertically Differentiated Markets with Costly UnderProvisioning: The Case of Versioning in Software Industry, Working paper, U. C. Irvine.

Stokey, N. (1979). Intertemporal Price Discrimination. Quaterly Journal of Economics, 93(3), 355-371.

Varian, H. R. (2001a). Markets for Information Goods, in Okina, K., ed., Monetary Policy in a World of Knowledge-Based Growth, Quality Change and Uncertain Measurement. Macmillan Press.

Varian, H. R. (2001b). Versioning Information Goods, in Kahin, B., Varian, H. R. eds., Internet Publishing and Beyond: The Economics of Digital Information and Intellectual Property. MIT Press.

Wei, X. and Nault, B. R. (2014). Monopoly Versioning of Information Goods When Consumers Have Group Tastes. Production and Operations Management, 23 (6), 1067-1081. DOI: 10.1111/poms.12180. 